\title{
Retrospective study on the effects of immunosuppressive therapy in uveitis associated with rheumatic diseases in Korea
}

\author{
Sang Yeob Lee $\cdot$ Won Tae Chung $\cdot$ Woo Jin Jung $\cdot$ \\ Sung Won Lee
}

Received: 17 August 2011 / Accepted: 10 December 2011 / Published online: 24 December 2011

(C) The Author(s) 2011. This article is published with open access at Springerlink.com

\begin{abstract}
This retrospective study of 432 patients was conducted between 2000 and 2009 to compare immunosuppressive therapy responses in uveitis accompanied or unaccompanied by rheumatic diseases. We divided patients into two groups: uveitis related or unrelated to rheumatic diseases. The clinical improvement after treatment was measured at the end of the observation period. Of the 432 patients with uveitis, $33(7.6 \%)$ patients suffered from associated rheumatic diseases and 399 (92.4\%) patients did not. The groups showed similar clinical features, but the mean age at onset of uveitis was lower in the rheumatic disease group ( $44.06 \pm 2.13$ years vs. $48.23 \pm 0.81$ years $)$. The rheumatic diseases included spondyloarthropathy (31\%), Behcet's disease (27\%), rheumatoid arthritis (18\%), systemic lupus erythematosus (15\%), Sjogren's syndrome (6\%), and mixed connective tissue disease (3\%). Erythrocyte sedimentation rate and C-reactive protein level were increased in uveitis associated with rheumatic diseases, whereas ocular complications were not. The response to immunosuppressive therapy was significantly increased in cases of uveitis associated with rheumatic diseases $(P<0.05)$. Therefore, during early treatment, uveitis accompanied by rheumatic diseases showed better response to immunosuppressive therapy and less frequent complications.
\end{abstract}

Keywords Uveitis - Rheumatic disease

S. Y. Lee $\cdot$ W. T. Chung $\cdot$ S. W. Lee $(\bowtie)$

Division of Rheumatology, Department of Internal Medicine, Dong-A University College of Medicine, 3-1 Dongdaesin-Dong, Seo-Gu, Busan 602-715, South Korea

e-mail: leesw@dau.ac.kr

W. J. Jung

Department of Ophthalmology, College of Medicine,

Dong-A University Hospital, Busan, Korea

\section{Introduction}

The eye is often overlooked by rheumatologists. Anatomically, the uvea is the middle layer of the eye, sandwiched between the sclera on the outside and the retina on the inside. The anterior uvea consists of the iris, which forms the pupil, and the ciliary body where aqueous humor is synthesized. The posterior uvea is the choroid, a richly vascular tissue adjacent to the retina. Subsets of uveitis can be anatomically defined, as follows: iritis, iridocyclitis, choroiditis, chorioretinitis, and panuveitis [1,2].

The uveal inflammation can result from a condition which involves the eye alone or can be caused by a variety of systemic infections, such as toxoplasmosis and herpes simplex. Anterior uveitis is among the common manifestations of eye disease in patients with seronegative spondyloarthropathy [3]. Information regarding the frequency of uveitis associated with adult rheumatic inflammatory autoimmune disease largely originates from ophthalmology departments of tertiary hospitals where $9-40 \%$ of uveitis was associated with adult rheumatic inflammatory autoimmune disease [4-6]. In the majority of cases, uveitis is acute, with symptoms duration of less than 3 months and good prognosis. In chronic and recurrent cases, however, visual acuity may be impaired due to several complications, such as cataract, secondary glaucoma, or cystoid macular edema. In western countries, it has been estimated that uveitis causes about $5 \%$ of blindness [7]. Due to increasing life expectancy, the proportion of senile degenerative conditions as a cause of blindness will likely continue to increase and, correspondingly, the share of most other conditions, including uveitis, decreases, particularly in incidence series. Nevertheless, scarce information is available on the relative importance of different uveitis entities as a cause of visual impairment $[8,9]$. 
Uveitis may present as a simple single disease, as well as a complicated disease related to various systemic disorders. Thus, uveitis may be considered as unexplained if the ophthalmologist did not detect systemic involvement at the time of initial manifestation. In some patients, uveitis is associated with infection and parasitic disease, depending on geographic location, race, and climate [10-14].

The aim of this study was to describe the frequency of uveitis associated with rheumatic inflammatory autoimmune disease in adult patients seen in the rheumatology department in a tertiary hospital in Busan, Korea, and to compare with uveitis unaccompanied by rheumatic disease in their clinical characteristics, treatment response, and eye complications.

\section{Patients and methods}

This observational study was conducted in 432 patients diagnosed with uveitis who visited the rheumatologic department for the evaluation of rheumatic disease, between 2000 and 2009. The diagnosis of uveitis was established in patients who met the diagnostic criteria of the International Uveitis Study Group (IUSG) certified in the Uveitis Section of the Ophthalmology Department, and who, in addition, were diagnosed with rheumatic inflammatory autoimmune disease that fulfilled the accepted classification criteria [15, 16]. Excluded from the study were records from foreign patients, patients with degenerative rheumatic diseases and metabolic diseases, and patients with uveitis caused by other etiologies, such as postoperative uveitis, keratouveitis, and purulent infections.

The ocular disease diagnosed at the patient's first visit was classified as anterior uveitis (iritis, iridocyclitis), intermediate uveitis (inflammation of peripheral retinal and pars plana of the ciliary body), posterior uveitis (choroiditis, chorioretinitis), or panuveitis (generalized inflammation of the whole uvea). The patients were divided into two groups: patients suffering from uveitis related to rheumatic diseases and patients diagnosed only with uveitis. All patients with rheumatic diseaserelated uveitis underwent special tests and diagnostic workups. These tests included antinuclear antibody (ANA), HLAB27, rheumatoid factor (RF), radiography of the sacroiliac joints, gallium-67 whole body scintigraphy, conjunctival and lacrimal gland biopsy, Mantoux test, and serum-specific antiparasitic and antiviral antibodies.

We used the American College of Rheumatology (ACR) criteria for the diagnosis of rheumatic disease. The following data were obtained from patients' records: age, sex, type of uveitis, and age at presentation of the first episode of uveitis. On the first visit to the ophthalmologist, the type of uveitis, erythrocyte sedimentation rate (ESR), and Creactive protein (CRP) were checked. At the final ophthalmic evaluation, the ocular sequelae and response to treat- ment were recorded. Data analysis was performed using the chi-squared $\left(\chi^{2}\right)$ test for statistical analysis, and $P$ values $<0.05$ were considered as statistically significant. All statistical analyses were performed using the SPSS software version 11.0 (SPSS Inc., Chicago, IL, USA).

\section{Results}

Of the 432 patients diagnosed with uveitis, 33 (8.27\%) patients had rheumatic disease-related uveitis and 399 $(91.73 \%)$ suffered only from uveitis. There was no significant difference between the groups in gender, mean age at onset, body mass index, underlying medical diseases, smoking, and alcohol intake. However, location of uveitis, the peak age at onset of uveitis, the degree of systemic inflammation, detection of autoantibodies, and the response to immunosuppressive treatment were different between each subject.

Uveitis accompanied rheumatic disease

In our study, $33(8.27 \%)$ patients showed uveitis related to rheumatic disease. The most common rheumatic disease associated with uveitis was ankylosing sponylitis (31\%), followed by Behcet's disease $(27 \%)$, rheumatic arthritis (18\%), SLE (15\%), Sjögren syndrome (6\%), and mixed connective tissue disease (3\%) (Fig. 1). The male to female ratio in this group was $17 / 16$ (52\% men). The mean age was $44.06 \pm 2.13$ years, and the average body mass index (BMI) was $22.32 \pm 0.88 \mathrm{~kg} / \mathrm{m}^{2}$. In general, anterior uveitis was more common than uveitis located at other sites; however, posterior uveitis was more common in this group, compared with uveitis unrelated to rheumatic disease (Table 1). The ESR and CRP levels were increased in this group, and the difference was statistically significant (Table 2). There was statistically significant difference in the positivity of antinuclear antibody, cryoglobulin, and HLA-B27, but the antineutrophil cytoplasmic antibody, anti-double-strand DNA antibody, and rheumatoid factor

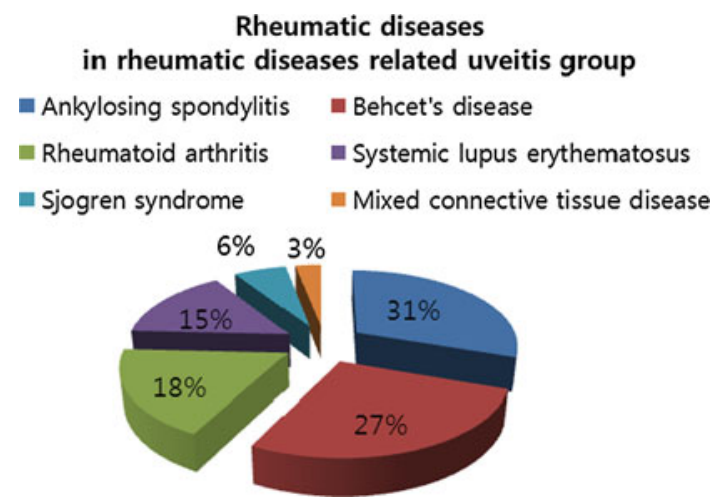

Fig. 1 Types of rheumatic diseases found to be related to uveitis 
Table 1 Demographic and clinical characteristics in the rheumatic disease-related uveitis and simple uveitis groups

\begin{tabular}{|c|c|c|c|}
\hline & $\begin{array}{l}\text { RD-related } \\
\text { uveitis group }\end{array}$ & $\begin{array}{l}\text { RD-unrelated } \\
\text { uveitis group }\end{array}$ & $P$ value \\
\hline Sex & $\begin{array}{l}\text { Male: } 17(52 \%), \\
\text { Female: } 16(48 \%)\end{array}$ & $\begin{array}{l}\text { Male: } 211(53 \%), \\
\text { Female: } 188(47 \%)\end{array}$ & \\
\hline \multicolumn{4}{|l|}{ Age } \\
\hline $\begin{array}{l}\text { Mean age } \\
\text { at onset }\end{array}$ & $44.06 \pm 2.13$ & $48.23 \pm 0.81$ & \\
\hline Total: $n(\%)$ & $33(100)$ & $399(100)$ & \\
\hline$<10$ & $0(0)$ & $0(0)$ & \\
\hline $10-19$ & $0(0)$ & $15(3.8)$ & \\
\hline $20-29$ & $3(9)$ & $39(3.8)$ & \\
\hline $30-39$ & $10(30.3)$ & $74(8.5)$ & \\
\hline $40-49$ & $8(24.2)$ & $79(19.8)$ & \\
\hline $50-59$ & $8(24.2)$ & $81(20.3)$ & \\
\hline $60-75$ & $4(12.1)$ & $111(27.8)$ & \\
\hline $\operatorname{BMI}\left(\mathrm{kg} / \mathrm{m}^{2}\right)$ & $22.32 \pm 0.880$ & $23.56 \pm 0.271$ & \\
\hline \multicolumn{4}{|c|}{ Underlying diseases } \\
\hline HT & $4(12 \%)$ & $64(16 \%)$ & 0.382 \\
\hline $\mathrm{DM}$ & $1(3 \%)$ & $32(8 \%)$ & 0.272 \\
\hline HBV & $2(6.1 \%)$ & $13(3.3 \%)$ & 0.315 \\
\hline $\mathrm{HCV}$ & $1(3 \%)$ & $1(0.3 \%)$ & 0.147 \\
\hline Smoke & $5(18 \%)$ & $77(19 \%)$ & 0.376 \\
\hline Alcohol & $5(18 \%)$ & $72(18 \%)$ & 0.445 \\
\hline \multicolumn{4}{|c|}{ Location of uveitis } \\
\hline Anterior & $14(42 \%)$ & $178(45 \%)$ & 0.478 \\
\hline Intermediate & $5(15 \%)$ & $47(12 \%)$ & 0.364 \\
\hline Posterior & $6(18 \%)$ & $27(6.7 \%)$ & 0.031 \\
\hline Panuveitis & $8(25 \%)$ & $147(36.3 \%)$ & 0.102 \\
\hline
\end{tabular}

$R D$ rheumatic disease, $B M I$ body mass index, $H T$ hypertension, $D M$ diabetes mellitus, $H B V$ hepatitis $\mathrm{B}$ virus, $H C V$ hepatitis $\mathrm{C}$ virus

Table 2 Information regarding association between autoantibody and inflammatory markers in uveitis

\begin{tabular}{llll}
\hline & RD-related uveitis & RD-unrelated uveitis & $P$ value \\
\hline ANA & $7(21 \%)$ & $32(8 \%)$ & 0.021 \\
Anti-ds DNA & $2(6 \%)$ & $4(1 \%)$ & 0.070 \\
ANCA & $1(3 \%)$ & $0(0 \%)$ & 0.076 \\
Cryoglobulin & $3(9 \%)$ & $4(1 \%)$ & 0.012 \\
HLA B27 & $7(21 \%)$ & $22(5.5 \%)$ & 0.004 \\
ESR $>20$ & $12(36.3 \%)$ & $65(16.3 \%)$ & 0.007 \\
ESR $\leq 20$ & $21(63.4 \%)$ & $334(83.7 \%)$ & \\
CRP $>0.5$ & $10(30.3 \%)$ & $63(15.8 \%)$ & 0.035 \\
CRP $\leq 0.5$ & $23(69.7 \%)$ & $336(84.2 \%)$ & \\
Total & 33 & 399 & \\
\hline ANA & &
\end{tabular}

$A N A$ anti nuclear antibody, ANCA anti neutrophil cytoplasmic antibody, ESR erythrocyte sedimentation rate, $C R P$ C-reactive protein were not significantly different (Table 2). Steroid was the important treatment drug, and high dose of systemic steroid therapy was applied in $22(67 \%)$ patients. Combined cyclosporine and topical steroid treatment was used in 20 patients (61\%) (Table 3). The most frequent ocular complications were cataract and retinal vacuities; the incidence of complications was lower than in the comparison group, but the difference was not statistically significant (Table 4).

Uveitis unaccompanied rheumatic disease

In our study, 399 (91.73\%) patients were diagnosed with uveitis not associated with rheumatic disease. The age ranged from 10 to 70 years, and many elderly patients (aged over 60 years) were in this group (Fig. 2). The male to female ratio was $211 / 188$ (53\% men). The mean age was $48.23 \pm 0.80$ years, and the average BMI was $23.56 \pm 0.27 \mathrm{~kg} / \mathrm{m}^{2}$. Diabetes mellitus and hypertension were the most common comorbid conditions, and the most common location was anterior uveitis (Table 1). The ESR and CRP levels were lower than in uveitis associated with rheumatic disease. There was no difference in positivity of antinuclear antibody, antinuclear cytoplasmic antibody, and cryoglobulin, compared to the other group (Table 2). Highdose steroid therapy was used in 150 patients (38\%), and the immunosuppressive drug cyclosporine was used in 29 patients $(7.3 \%)$. Combined topical and systemic steroid treatment was conducted in 183 patients $(46 \%)$, as presented in Table 3. The most frequent ocular compilations were cystoid macular edema, cataract, retinal vasculitis, optic neuritis, and glaucoma. The incidence of ocular complications was higher than in the other group, but the difference was not statistically significant (Table 4).

\section{Discussion}

Eye inflammation may be a prominent feature of several rheumatic diseases, such as spondyloarthropathy and Behcet's disease; therefore, some ophthalmologist focused mainly on rheumatic disease as a cause of uveitis [11-13].

Our objective in this study was to analyze the type of rheumatic disease associated with uveitis and its relationship with systemic inflammation, autoantibody, treatment drugs, and incidence of ocular complications. This report based on patient records shows that, in adults (aged over 16 years), uveitis was associated with various rheumatic inflammatory autoimmune diseases. Infection as a cause of uveitis was initially ruled out. Because of peripheral joint pain and/or low-intensity back pain, asthenia, and adynamia, the patients were initially seen by a general practitioner, who diagnosed infectious or allergic conjunctivitis, 
Table 3 Combined steroid and immunosuppressive treatment in uveitis

\begin{tabular}{llll}
\hline & RD-related uveitis & RD-unrelated uveitis & P value \\
\hline Topical steroid & Applied: $31(94 \%)$ & Applied: $314(79 \%)$ & 0.022 \\
& Not applied: $2(6 \%)$ & Not applied: $85(21 \%)$ & \\
Periocular steroid & Applied: $10(30 \%)$ & Applied: 27 (6.8\%) & $<0.000$ \\
& Not applied: $23(70 \%)$ & Not applied: 372 (93.2\%) & \\
Steroid treatment & & & 0.018 \\
High-dose oral steroid & Applied: $22(67 \%)$ & Applied: $150(38 \%)$ & 0.001 \\
& Not applied: $11(33 \%)$ & Not applied: $249(62 \%)$ & \\
Immunosuppressive agent & Applied: $23(94 \%)$ & Applied: $29(7.3 \%)$ & $<0.000$ \\
& Not applied: $10(6 \%)$ & Not applied: $370(92.7 \%)$ & \\
Combination Tx & Applied: $20(61 \%)$ & Applied: $183(46 \%)$ & 0.074 \\
(topical + systemic) & Not applied: $13(39 \%)$ & Not applied: $216(54 \%)$ & \\
\hline
\end{tabular}

Table 4 Information regarding association of the incidence of ocular complications in the rheumatic disease-related uveitis and simple uveitis groups

\begin{tabular}{|c|c|c|c|}
\hline & RD-related uveitis & RD-unrelate & $P$ value \\
\hline $\begin{array}{l}\text { Cystoid macular } \\
\text { edema }\end{array}$ & $\begin{array}{l}\text { Present: } 0(0 \%) \\
\text { Absent: } 33(100 \%)\end{array}$ & $\begin{array}{l}\text { Present: } 8(2 \%) \\
\text { Absent: } 391(98 \%)\end{array}$ & 0 \\
\hline Cataract & $\begin{array}{l}\text { Present: } 1(3 \%) \\
\text { Absent: } 32(97 \%)\end{array}$ & $\begin{array}{l}\text { Present: } 42(10.5 \%) \\
\text { Absent: } 357(89.5 \%)\end{array}$ & 0.13 \\
\hline Retinal vasculitis & $\begin{array}{l}\text { Present: } 1(3 \%) \\
\text { Absent: } 32(97 \%)\end{array}$ & $\begin{array}{l}\text { Present: } 7(1.8 \%) \\
\text { Absent: } 392(98.2 \%)\end{array}$ & 0.571 \\
\hline Ontic & $\begin{array}{l}\text { Present: } 0(0 \%) \\
\text { Absent: } 33(100 \%)\end{array}$ & $\begin{array}{l}\text { Present: } 7(1.8 \%) \\
\text { Absent: } 392(98.2 \%)\end{array}$ & 0.571 \\
\hline $\begin{array}{l}\text { Secondary } \\
\text { glaucoma }\end{array}$ & $\begin{array}{l}\text { Present: } 0(0 \%) \\
\text { Absent: } 33(100 \%)\end{array}$ & $\begin{array}{l}\text { Present: } 23(5.8 \%) \\
\text { Absent: } 376(94.2 \%)\end{array}$ & 0.153 \\
\hline $\begin{array}{l}\text { Posterior } \\
\text { synechiae }\end{array}$ & $\begin{array}{l}\text { Present: } 0(0 \%) \\
\text { Absent: } 33(100 \%)\end{array}$ & $\begin{array}{l}\text { Present: } 7(1.8 \%) \\
\text { Absent: } 392(98.2 \%)\end{array}$ & 0.571 \\
\hline
\end{tabular}

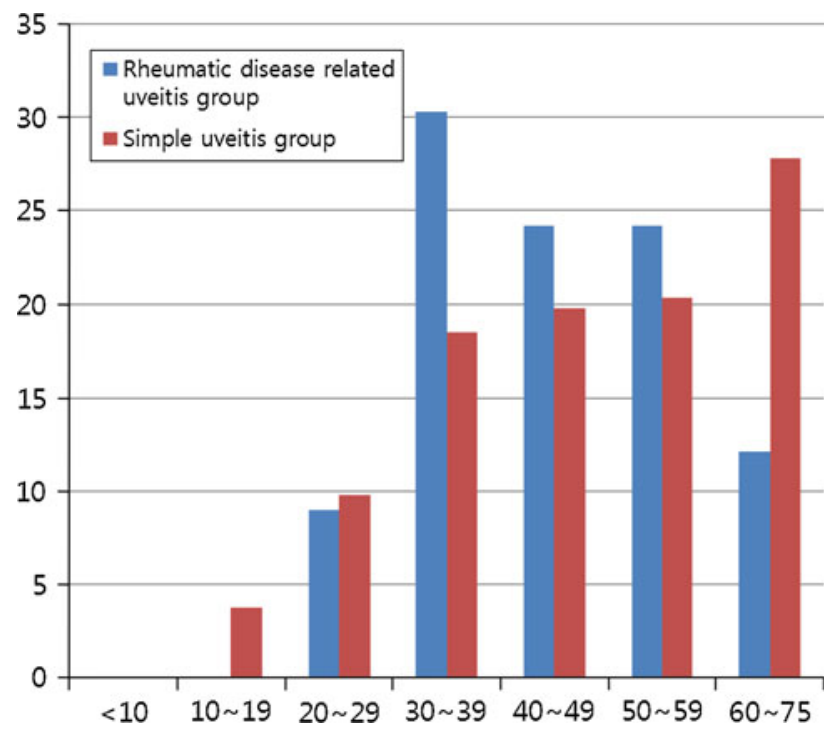

Fig. 2 The peak age of onset of rheumatic disease-related uveitis was in the third, fourth, and fifth decades, in $78.7 \%$ patients of our series between 30 and 50 years of age. In contrast, the peak age of onset of simple uveitis was over 60 years, showing that the prevalence of simple uveitis was proportionate with age resulting in a delay of weeks or even months before examination by an ophthalmologist specialized in ocular inflammatory diseases. Upon the diagnosis of uveitis, the ophthalmologist began treatment with topical steroids and directed patients to the rheumatologist. Because of the large number of patients being treated in the rheumatology outpatient department, the delay to see the rheumatologist was 7-15 days. At the time of rheumatologic evaluation, extraocular symptoms had disappeared and laboratory and image studies were normal; thus, it was not usually possible to establish the diagnosis of rheumatic inflammatory autoimmune disease from the outset (or at first episode of uveitis).

The cause of uveitis was unknown, but it usually follows the mechanisms of action in which the eye is affected by autoimmune activation in up to $40 \%$ of cases. Thus, uveitis is part of a multisystemic disease, rather than isolated, organ-specific. In the future, some of the $60 \%$ idiopathic cases might prove to be autoimmune in nature [17].

The anterior chamber response is characteristic of autoimmune diseases, whereas the prevalence of infectious causes is higher in posterior uveitis. In our study, anterior uveitis was more common than posterior uveitis in both groups. However, the uveitis related to rheumatic disease was more common in posterior location than uveitis unrelated to rheumatic disease.

The mean age of patients was similar in the two groups, but the onset age of uveitis associated with rheumatic disease was younger. The age distribution of patients in the rheumatic disease-related uveitis group was 10-60 years, but old-aged patients were more common than in uveitis unrelated to rheumatic disease. Diabetes mellitus and hypertension were the most common comorbid conditions in uveitis unrelated to rheumatic disease.

Detection of elevated antinuclear antibodies (ANA) can be useful for the positive diagnosis [18]. The positive results of ANA, anti-ds DNA, ANCA, and HLA B27 show the possibility of underlying rheumatic diseases. Therefore, when a patient is diagnosed with uveitis, the patient should 
be routinely checked for ANA, anti-ds DNA, ANCA, and HLA-B27.

HLA associations have been observed in many types of uveitis. Associations include HLA-B27 in acute anterior uveitis, HLA-B51 in Behçet's disease, and HLA-B44 in occlusive vasculitis. A recent study in Behçet's disease patients showed that those with active uveitis had a significant response to B27PD (a peptide derived from HLA-B27 with homology for HLA-B51), as compared with Behçet's disease patients without uveitis, or normal controls [1923]. Autoantibodies do not seem to play an active role in the induction phase of the disease. Evidence for this is derived from various sources. The study of human pathologic specimens reveals the presence of infiltrating CD4+, but not B cells in the early phase of Behçet's disease and sarcoidosis. The presence of circulating immune complexes in Behçet's disease is associated with a better prognosis or is a sign of good control by medication. These findings suggest that antibodies in uveitis have a regulatory, or possibly even a protective role. The presence of a sufficient level of antibodies may even prevent recurrences, but this remains to be demonstrated [24, 25].

The ESR and CRP levels represent systemic inflammation, and they were higher in uveitis associated with rheumatic disease. It showed that this type of uveitis was a systemic inflammatory disease.

The decision of adequate therapy for patients with uveitis is difficult because of the lack of guidelines and the paucity of randomized, controlled clinical trials. Treatment decisions should include the compartment of inflammation. Topical corticosteroid eye drops are reserved for anterior uveitis. Periocular injections of steroid can be administered if the inflammation is unilateral. Because of their better penetration into the posterior ocular tissues, injections should be considered in posterior uveitis, whereas topical eye drops are usually effective in anterior uveitis. In severe bilateral intermediate or posterior uveitis, immunosuppressive therapy is indicated. The drug of choice is high-dose systemic corticosteroids, followed by slow tapering of dosage, with or without the addition of another immunosuppressive, steroid-sparing agent, such as methotrexate or cyclosporine [26, 27]. Corticosteroids should be tapered with close follow-up, rather than continuing prolonged topical steroids, in an attempt to eliminate any sign of anterior chamber reaction.

Recently, guidelines for the use of immunosuppressive drugs for inflammatory eye disease were established and include corticosteroids, azathioprine, methotrexate, mycophenolate mofetil, cyclosporine, tacrolimus, cyclophosphamide, and chlorambucil. Azathioprine and/or cyclosporine are effective in the management of ocular inflammation in Behçet's disease, as open-label trials suggest a high rate of clinical response. Sulfasalazine was reported to ameliorate the severity and prevent recurrences of anterior uveitis associated with HLA B27 [28-30].

The incidence of ocular complications was lower in the rheumatic disease-related uveitis group, although the difference was not statistically significant. It was inferred that uveitis related to rheumatic disease was a more severe inflammatory disease, so the response to immunosuppressive therapy was more effective in this group.

We believe that, in a patient diagnosed with uveitis, the relationship with autoimmune disease should be considered at early stage; consequently, rapid and appropriate application of steroid and immunosuppressive agents in uveitis associated with rheumatic disease could prevent ocular complications. Future studies will be required to ascertain the relationship between uveitis and rheumatic disease.

Acknowledgments This work was supported by the Dong-A University research fund.

Conflict of interest The authors declare that they have no conflict of interests related to this work.

Open Access This article is distributed under the terms of the Creative Commons Attribution Noncommercial License which permits any noncommercial use, distribution, and reproduction in any medium, provided the original author(s) and source are credited.

\section{References}

1. Wakefield D, Chang JH (2005) Epidemiology of uveitis. Int Ophthalmol Clin 45:1-13

2. Donaldson MJ, Pulido JS, Herman DC et al (2007) A 20-year study of incidence, clinical features, and outcomes. Am J Ophthalmol 144:812-817

3. Ali A, Samson CM (2007) Seronegative spondyloarthropathies and the eye. Curr Opin Ophthalmol 18:476-480

4. Sengun A, Karadag R, Karakurt A et al (2005) Causes of uveitis in a referral hospital in Ankara, Turkey. Ocul Immunol Inflamm 13:45-50

5. Kotaniemi K, Aho K, Kotaniemi A (2001) Uveitis as a cause of visual loss in arthritides and comparable conditions. J Rheumatol 28:309-312

6. Pras E, Neumann R, Zandman GG et al (2004) Intraocular inflammation in autoimmune diseases. Semin Arthritis Rheum 34:602609

7. Doesschate TJ (1982) Causes of blindness in The Netherlands. Doc Ophthalmol 52:279-285

8. Rothova A, Buitenhuis HJ, Meenken C et al (1992) Uveitis and systemic disease. Br J Ophthalmol 76:137-141

9. Rothova A, Suttorp-van Schulten MSA et al (1996) Causes and frequency of blindness in patients with intraocular inflammatory disease. Br J Ophthalmol 80:332-336

10. Chang JH, Wakefield D (2002) Uveitis: a global perspective. Ocul Immunol Inflamm 10:263-279

11. Mercanti A, Parolini B, Bonora A et al (2001) Epidemiology of endogenous uveitis in north-eastern Italy. Analysis of 655 new cases. Acta Ophthalmol Scand 79:64-68

12. Stan C (2000) The influence of meteorological factors in wintertime on the incidence of the occurrence of acute endogenous iridocyclitis. Oftalmologia 52:16-21 
13. Levinson RD, Greenhill LH (2002) The monthly variation in acute anterior uveitis in a community-based ophthalmology practice. Ocul Immunol Inflamm 10:133-139

14. Yagev R, Tsumi E, Avigur J et al (2005) The effect of the Dead Sea environment on uveitis. Isr Med Assoc J 7:86-90

15. Nussenblatt RB (1987) International Uveitis study group recommendations for the evaluation of intraocular inflammatory disease. Am J Ophthalmol 103:234-235

16. McAdam LP, O'Hanlan MA, Bluestone R et al (1976) Relapsing polychondritis: prospective study of 23 patients and a review of the literature. Medicine 55:193-215

17. Pras E, Neumann R, Zandman-Goddard G et al (2004) Intraocular inflammation in autoimmune diseases. Semin Arthritis Rheum 34:602-609

18. Murray P (1986) Serum autoantibodies and uveitis. Br J Ophthalmol 70:266-268

19. Davey MP, Rosenbaum JT (2000) The human leukocyte antigen complex and chronic ocular inflammatory disorders. Am J Ophthalmol 129:235-243

20. Huhtinen M, Karma A (2000) HLA-B27 typing in the categorization of uveitis in a HLA-B27 rich population. Br J Ophthalmol $84: 413-416$

21. Chajek-Shaul T, Pisanty S, Knobler H et al (1984) HLA-B51 may serve as an immunogenic marker for a subgroup of patients with Behcet's syndrome. Am J Med 83:666-672

22. Kilmartin DJ, Finch A, Acheson RW (1997) Primary association of HLA-B51 with Behcet's disease in Ireland. Br J Ophthalmol 81:649-653
23. Ishihara M, Ishida T, Mizuki N et al (1995) Clinical features of sarcoidosis in relation to HLA distribution and HLA-DRB3 genotyping by PCR-RFLP. Br J Ophthalmol 79:322-325

24. Charteris DG, Barton K, McCartney AC et al (1992) CD4 ${ }^{+}$lymphocyte involvement in ocular Behcet's disease. Autoimmunity 12:201-206

25. Chan CC, Wetzig RP, Palestine AG et al (1987) Immunohistopathology of ocular sarcoidosis. Report of a case and discussion of immunopathogenesis. Arch Ophthalmol 105:1398-1402

26. Smith JR, Rosenbaum JT (2002) Management of uveitis: a rheumatologic perspective. Arthritis Rheum 46:309-318

27. Whitcup SM, Salvo EC Jr, Nussenblatt RB (1994) Combined cyclosporine and corticosteroid therapy for sight-threatening uveitis in Behcet's disease. Am J Ophthalmol 118(1):39-45

28. Jabs DA, Rosenbaum JT, CS Foster et al (2000) Guidelines for the use of immunosuppressive drugs in patients with ocular inflammatory disorders: recommendations of an expert panel. Am J Ophthalmol 30:492-513

29. Yazici H, Pazarli H, Barnes CG et al (1990) A controlled trial of azathioprine in Behcet's syndrome. N Engl J Med 322(5):281-285

30. Benitez-Del-Castillo JM, Garcia-Sanchez J, Iradier T (2000) Sulfadiazine in the prevention of anterior uveitis associated with ankylosing spondylitis. Eye (Lond) 14(Pt 3A):340-343 